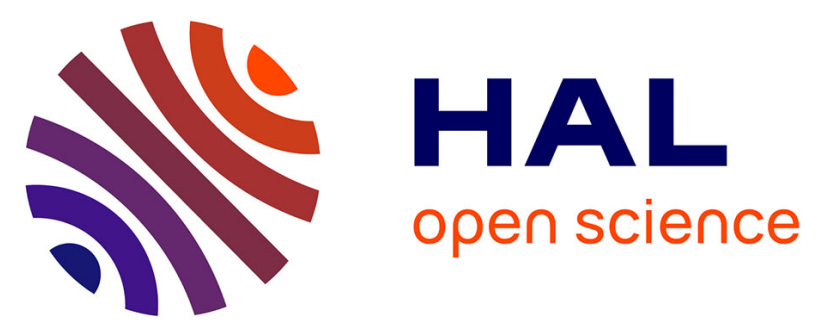

\title{
Echocardiographic features in antiphospholipid-negative Sneddon's syndrome and potential association with severity of neurological symptoms or recurrence of strokes: a longitudinal cohort study
}

Florence Assan, Dominique de Zuttere, Laure Bottin, Sebastian Tavolaro, Delphine S Courvoisier, Annick Barbaud, Sonia Alamowitch, Camille Francès, François Chasset

\section{- To cite this version:}

Florence Assan, Dominique de Zuttere, Laure Bottin, Sebastian Tavolaro, Delphine S Courvoisier, et al.. Echocardiographic features in antiphospholipid-negative Sneddon's syndrome and potential association with severity of neurological symptoms or recurrence of strokes: a longitudinal cohort study. European Heart Journal - Cardiovascular Imaging, 2021, 22 (1), pp.119-128. 10.1093/ehjci/jez312 . hal-03334455

\section{HAL Id: hal-03334455 \\ https://hal.sorbonne-universite.fr/hal-03334455}

Submitted on 3 Sep 2021

HAL is a multi-disciplinary open access archive for the deposit and dissemination of scientific research documents, whether they are published or not. The documents may come from teaching and research institutions in France or abroad, or from public or private research centers.
L'archive ouverte pluridisciplinaire HAL, est destinée au dépôt et à la diffusion de documents scientifiques de niveau recherche, publiés ou non, émanant des établissements d'enseignement et de recherche français ou étrangers, des laboratoires publics ou privés. 
1 Title: Echocardiographic features in antiphospholipid-negative Sneddon's syndrome and

2 potential association with severity of neurological symptoms or recurrence of strokes: a

3

4

5

Florence Assan, $\mathrm{MD}^{1 *}$, Dominique de Zuttere, $\mathrm{MD}^{2 *}$, Laure Bottin, $\mathrm{MD}^{3}$, Sebastian Tavolaro, $\mathrm{MD}^{4}$, Delphine S. Courvoisier, $\mathrm{PhD}^{5}$, Annick Barbaud, $\mathrm{MD}, \mathrm{PhD}^{1}$, Sonia Alamowitch, $\mathrm{MD}^{3}$, Camille Francès, $\mathrm{MD}^{1}$, François Chasset, $\mathrm{MD}^{1}$

${ }^{1}$ Sorbonne Université, Faculté de Médecine Sorbonne Université, AP-HP, Service de

Dermatologie et Allergologie, Hôpital Tenon, F-75020 Paris, France

${ }^{2}$ Service d'Explorations Fonctionnelles, Hôpital Franco-Britannique, Levallois-Perret, France

${ }^{3}$ Sorbonne Université, Faculté de Médecine Sorbonne Université, AP-HP, Service de Neurologie, Hôpital Saint-Antoine, F-75012, Paris, France

${ }^{4}$ Sorbonne Université, Faculté de Médecine Sorbonne Université, AP-HP, Service de Radiologie, Hôpital Tenon, F-75020, Paris, France

${ }^{5}$ Division of rheumatology, Department of Medicine, University of Geneva

\section{Corresponding author \& reprint requests:}

François Chasset, MD, Sorbonne université, AP-HP, Service de Dermatologie et d'Allergologie, Hôpital Tenon, 4 rue de la Chine 75970 Paris CEDEX 20, France

Phone number: (+33156 0175 47). Fax number: (+331 560172 32)

Email: francois.chasset@gmail.com

Conflict of interest: None; Funding sources: None

* contributed equally to the work and shared the first authorship

\section{Introduction}


Sneddon's syndrome (SS) is a rare non-inflammatory thrombotic vasculopathy characterized by the association of cerebrovascular thrombosis with livedo racemosa (LR) $\left({ }^{1}\right)$. SS has been described mostly in women between age 20 and 40 years $\left({ }^{1}\right)$, and its estimated incidence is about 4 per 1 million per year in the general population $\left({ }^{2}\right)$. SS can be classified in two subgroups: with antiphospholipid antibodies (aPL) $\left(\mathrm{aPL}^{+} \mathrm{SS}\right)$ and without aPL $\left(\mathrm{aPL}^{-} \mathrm{SS}\right)$. Indeed, in about $50 \%$ of cases ( 0 to $85 \%$ depending on the series), SS is associated with aPL $\left({ }^{2,3}\right)$ and thus could be classified as antiphospholipid syndrome (APS) $\left({ }^{4-9}\right)$.

Heart valve disease (HVD) is frequently observed in both SS with and without aPL $\left({ }^{10,11}\right)$. Indeed, Francès et al. $\left({ }^{10}\right)$ found HVD or valve thickening in both $\mathrm{aPL}^{+}$and $\mathrm{aPL}^{-} \mathrm{SS}$ patients, in more than $50 \%$ of cases. Of note, in $\mathrm{aPL}^{+}$patients (both systemic lupus erythematosus (SLE) and primary APS patients), an increased risk of stroke, transient ischemic attack (TIA) or neurocognitive dysfunction have been reported in patients with HVD, particularly those with Libman-Sacks (LS) endocarditis $\left({ }^{12-16}\right)$. A high prevalence of LS endocarditis $(25 \%)$ has also been reported in a sample of $40 \mathrm{aPL}^{-} \mathrm{SS}$ patients $\left({ }^{17}\right)$, though there was no association between LS and the pattern of strokes (middle-size arteries, superficial perforating arteries, and deep perforating arteries). However, this study did not assess specifically the role of cardiac involvement in $\mathrm{aPL}^{-} \mathrm{SS}$, particularly the impact of LS endocarditis on the type and/or severity of neurological involvement. Moreover, the risk of recurrence of neurovascular events or the need to modify SS treatment in light of LS endocarditis development during-follow-up has not been assessed.

To address these questions, we analyzed echocardiographic data of a longitudinal cohort of aPL- SS patients with long-term follow-up. Specifically, we aimed to 1) describe the cardiac involvement of $\mathrm{aPL}^{-} \mathrm{SS}$ patients, 2) assess the impact of LS endocarditis at baseline on the type and severity of neurological involvement, 3) describe the prevalence and type of cardiac 
52 complications during long-term follow-up, and 4) assess the impact of LS endocarditis 53 development during follow-up on risk of neurological relapse.

54

55

56

57

58

59

60

61

62

63

64

65

66

67

68

69

70

71

72

73

74

75

76 
Patients and methods

Study design and setting

We analyzed echocardiographic data of a longitudinal cohort of aPL- SS patients followed in neurology and dermatology departments of French university hospitals between January 1991 and June 2018.

83

\section{Participants and eligibility criteria}

85

4

Patients were included if they were followed for $\mathrm{aPL}^{-} \mathrm{SS}$; did not have anticardiolipin antibodies, anti-beta2 glycoprotein 1 antibodies or lupus anticoagulant detected at a significant rate confirmed on at least 2 occasions and echocardiography at baseline.

Diagnosis of SS was based on the association of permanent LR (assessed by one expert senior dermatologist) and at least one stroke (cerebral infarct [CI], TIA, or a silent infarct, only visible as sequelae on brain imaging). Patients included in the previous study from our group describing strokes pattern were included if they had echocardiography at baseline $\left({ }^{17}\right)$. All patients had baseline transthoracic echocardiographic data, patients with unclear diagnosis $(n=3)$, for example suspicion of infectious cause of endocarditis, were excluded.

\section{Data collection and definitions}

Clinical data collected were cardiovascular risk factors, clinical manifestations including first clinical manifestations and neurological manifestations, and first-line treatment for SS. Neurological relapse defined by a recurrence of CI, TIA or silent infarct were systematically assessed clinically and by brain imaging data during annual follow-up or in case of suggestive clinical symptoms.

Biological data collected were hemoglobin A1C, total cholesterol and triglycerides levels; 
102

103

104

105

106

107

108

109

110

111

112

113

114

115

116

117

118

antinuclear antibodies and anti-native DNA antibodies by ELISA and Crithidia luciliae immunofluorescence; $\mathrm{C} 3, \mathrm{C} 4$ and $\mathrm{CH} 50$ activity; homocysteine level. aPL were tested annually during follow-up and negativity was defined according to 2006 Sydney criteria $\left({ }^{8}\right)$. Diagnosis of systemic lupus erythematosus (SLE) associated with SS was made according to the 2012 Systemic Lupus International Collaborating Clinics classification. $\left({ }^{18}\right)$ The reasons for antithrombotic treatment modifications during follow-up were assessed with focus on the potential association between the occurrence of LS endocarditis during follow-up and treatment escalation (switch from low-dose aspirin to vitamin-K antagonists).

Brain imaging data (MRI or CT) collected at diagnosis and during follow-up were reviewed, and neurological definitions were based on 2013 American Heart Association/American Stroke Association expert consensus $\left({ }^{19}\right)$. Silent infarction was defined by an imaging or neuropathological evidence of central nervous system infarction, without a history of acute neurological dysfunction attributable to the lesion. Hemorrhagic stroke was defined by a focal collection of chronic blood products within the brain parenchyma, subarachnoid space, or ventricular system on neuroimaging or neuropathological examination that was not caused by trauma. Carotid stenosis was evaluated either by carotid ultrasound or by aortic magnetic resonance imaging.

\section{Echocardiography}

All patients underwent comprehensive echocardiography including standard transthoracic 2-D and Doppler echocardiography studies by the same senior cardiologist (DZ) at diagnosis and during follow-up annually when available. Speckle-tracking echocardiography was also systematically used from the moment this technique became available in our laboratory (2007). Echocardiography assessments were performed using Vivid 7 and Vivid e9 ultrasound machines with M3s, M5sc-D and 4V-D probes (GE Healthcare, Milwaukee, WI), in accordance with the American Society of Echocardiography successive guidelines $\left({ }^{20,21}\right)$. Left ventricular 
127 (LV) internal dimensions and wall thickness, chamber volumes, and valvular morphology were

128

129

130

131

132

133

134

135 assessed. LS vegetations were identified as described by Roldan et al. $\left({ }^{16}\right)$, as abnormal localized, protruding, and sessile echodensities $>3 \mathrm{~mm}$ in diameter with well-defined borders as part of or adjacent to valve leaflets, annulus, subvalvular apparatus, or endocardial surfaces. LV ejection fraction (LVEF) was measured by the modified Teichholz method. Left atrial (LA) volume was calculated by the biplane method of disks and indexed to body surface area (BSA); left atrial volume index $>34 \mathrm{ml} / \mathrm{m}^{2}$ was used to define left atrial enlargement (LAE) $\left({ }^{20}\right)$. LV mass index (LVMi) was obtained from M-mode LV mass measurement with standard criteria and normalized for BSA $\left({ }^{20}\right)$. LV enlargement (LVE) was defined as end-diastolic diameter $>56$ mm (linear M-mode measurement) $\left({ }^{22}\right)$. LV hypertrophy (LVH) was defined as LVMi/BSA $>115 \mathrm{~g} / \mathrm{m}^{2}$ for men and $>95 \mathrm{~g} / \mathrm{m}^{2}$ for women. LV inflow was obtained by pulsed wave Doppler in the apical 4-chamber view; peak early (E) and late (A) diastolic velocities, deceleration time, and $\mathrm{E} / \mathrm{A}$ ratio were obtained. Peak early diastolic medial and lateral mitral annular velocity $\left(\mathrm{e}^{0}\right)$ and ratio of mitral-inflow early diastolic velocity to average e' velocity were obtained from pulsed tissue Doppler; E/e' $>13$ was used as a cutoff of diastolic dysfunction (DD) $\left({ }^{21}\right)$. For deformation imaging, standard grayscale 2-D images were acquired in conventional 4-, 2-, and 3-chamber view. Global longitudinal strain (GLS) was calculated by the average of 3 apical views with standard software $\left({ }^{22,23}\right)$. Cutoffs of $-16 \%$ for abnormal GLS were used $\left({ }^{24}\right)$. Stage B heart failure (SBHF) was defined by 1) DD (E/e' $>13), 2)$ LAE $\left.\left(>34 \mathrm{ml} / \mathrm{m}^{2}\right), 3\right) \mathrm{LVH}(>115$ $\mathrm{g} / \mathrm{m}^{2}$ for men, $>95 \mathrm{~g} / \mathrm{m}^{2}$ for women), and 4) impaired GLS (cutoff -16\%) $\left({ }^{24}\right)$. Pulmonary artery systolic pressure was calculated by adding an estimate of right atrial pressure (using inferior vena cava size and response to respiration) to the RV-RA gradient calculated using peak tricuspid regurgitation velocity. According to standard methods $\left({ }^{25}\right)$, aortic insufficiency was considered moderate to severe when two or more of the following semi-quantitative and quantitative criteria were present: vena contracta width $\geq 3 \mathrm{~mm}$, pressure half-time $\leq 500 \mathrm{~ms}$, 
152 effective regurgitant orifice $\geq 10 \mathrm{~mm}^{2}$, and regurgitant volume $\geq 30 \mathrm{~mL}$. Other factors

153 supporting lesion severity included the duration and eccentricity of the regurgitant jet. The final

154 determination of severity by the interpreting cardiologist incorporated all aspects of the imaging 155 and Doppler echocardiography study. The severity of aortic stenosis (AS) was evaluated 156 according to standard methods $\left({ }^{26}\right)$. Peak aortic jet velocity was derived from transaortic flow, 157 recorded with continuous wave Doppler using a multiwindow approach. Peak and mean 158 gradients were calculated by using the simplified Bernoulli equation. The continuity equation 159 was used to calculate aortic valve area (AVA). Moderate and severe AS were defined as AVA 1601.0 to $1.5 \mathrm{~cm}^{2}$ and $<1.0 \mathrm{~cm}^{2}$, respectively. Mitral valve prolapse (MVP) was defined as superior 161 displacement $2 \mathrm{~mm}$ of any part of the mitral leaflet beyond the mitral annulus according to the 162 American Society of Echocardiography guidelines $\left({ }^{26}\right)$. According to standard methods $\left({ }^{25}\right)$, 163 mitral regurgitation was considered moderate to severe with presence of two or more of the 164 following semi-quantitative and quantitative criteria: vena contracta width $\geq 3 \mathrm{~mm}$, effective 165 regurgitant orifice $\geq 20 \mathrm{~mm}^{2}$, regurgitant volume $\geq 30 \mathrm{~mL}$. The conventional indices for 166 assessment of the severity of mitral stenosis, such as mitral valve area (MVA) by planimetry 167 and pressure half-time and the maximum and mean mitral valve pressure gradients, were 168 measured as recommended $\left({ }^{27}\right)$.

\section{Statistical analysis}

170 Data are presented as median (range) or number (\%). We used chi-square or Fisher's exact test 171 (as appropriate) and Mann-Whitney test to compare categorical and unpaired non-normally 172 distributed quantitative data, respectively. Two-tailed $\mathrm{P}<0.05$ was considered statistically 173 significant. Kaplan-Meier survival curves were used to assess the risk of neurological relapses, 174 considering the time from first transthoracic echocardiography or occurrence of LS endocarditis 175 to last follow-up for censored individuals or to the occurrence of new stroke or TIA. Hazard 176 ratios (HRs) and 95\% confidence intervals (CIs) were estimated by Cox regression and survival 
177 curves were compared by the log-rank test. Analyses were performed with JMP v13 (SAS Inst.

178 Inc., Cary, NC)

179

180

181

182

183

184

185

186

187

188

189

190

191

192

193

194

195

196

197

198

199

200

201 
Results

\section{Patient characteristics}

205 We included 61 patients (52 women, median age at diagnosis 45 [range 24-60]). Demographic 206 and disease characteristics of included patients are summarized in Table 1. Full data including 207 individual clinical features, LS endocarditis status and treatment received of aPL- Sneddon, as 208 well as presence of relapse are provided as supplemental data. CI and TIA were the most 209 frequent initial clinical manifestations $(n=48,78.7 \%)$. The most common thrombotic neurological events were CI only $(n=40,65.6 \%)$, TIA only $(n=8,13 \%)$ and CI+TIA $(n=8,13 \%)$.

211 Other neurological symptoms included migraine $(n=22,36 \%)$, epilepsy $(n=13,21 \%)$ and 212 cognitive impairment $(\mathrm{n}=23,44 \%)$. For cardiovascular risk factors, $34(55.7 \%)$ patients had 213 high blood pressure, $30(49 \%)$ had BMI $>25 \mathrm{~kg} / \mathrm{m}^{2}$ and $35(57.4 \%)$ previously or currently 214 smoked tobacco. Only three patients presented a $\geq 50 \%$ carotid stenosis, and two patients with $215 \mathrm{a}<50 \%$ carotid stenosis inferior. Only one patient fulfilled criteria for SLE. Most patients 216 received low-dose aspirin as first-line treatment to prevent thrombotic neurological events $217 \quad(\mathrm{n}=44,72 \%)$.

Cardiac findings at baseline (Table 2)

220 For valvular involvement, $36(59 \%)$ patients showed leaflet thickening, including isolated 221 mitral valve thickening $(n=16,26 \%)$, isolated aortic valve thickening $(n=14,23 \%)$ and both 222 mitral and aortic thickening $(\mathrm{n}=6,10 \%)$. In total, $18(29.5 \%)$ patients showed LS endocarditis 223 (Figure 1) at baseline, including mitral LS endocarditis in $11(18 \%)$ and aortic LS endocarditis 224 in $9(14.75 \%)$. Median thickness of mitral and aortic LS endocarditis was $5 \mathrm{~mm}$ (range 3.7-7.0) 225 and $4 \mathrm{~mm}$ (range 3.0-5.3), respectively. Moreover, 25 (40.9\%) patients showed aortic 226 regurgitation (Figure 1-D), including 4 (6.6\%) with moderate to severe aortic regurgitation. 
227 Overall, 45 (73.8\%) patients showed mitral regurgitation (Figure 1-I), with moderate to severe 228 mitral regurgitation in $3(4.9 \%)$. For LV parameters, median EF at baseline was $69 \%$ (range $22952-86 \%)$; only $1(2 \%)$ patient had $\mathrm{EF}<53 \%$. Relaxation impairment was the most frequent LV 230 abnormality, observed in 24 (39\%) patients, and median peak longitudinal strain was -20.95 231 (range $-26.2--14.2)$; $1(1.7 \%$ ) patients had initial peak longitudinal strain $>-16 \%$. For SBHF 232 criteria, $47(80 \%)$ patients had at least one criterion, but none fulfilled all four criteria $\left({ }^{24}\right)$. 233 Median systolic pulmonary arterial pressure was $26.5 \mathrm{mmHg}$ (range 18-42); 3 (4.9\%) patients 234 had systolic pulmonary arterial pressure $>35 \mathrm{mmHg}$.

Comparison of demographic, clinical, biological and radiological features with and without LS endocarditis at baseline (Table 3)

238 Patients with and without LS endocarditis at baseline did not differ in socio-demographic or neurological features, including number of CI and TIA events at baseline or prevalence of migraine, epilepsy and cognitive impairment. At baseline, the number of TIA events was

241 marginally greater among patients with versus without LS endocarditis: median 2 (range 1-6)

242 versus $1(1-2) \mathrm{p}=0.06$.

243 The frequency of Raynaud phenomenon was higher with than without LS endocarditis at 244 baseline [13 (72\%) vs $16(37 \%), p=0.01]$. LS endocarditis was marginally associated with 245 prevalence of antinuclear antibodies $[\geq 1 / 160: 8(46 \%)$ vs $10(24 \%), p=0.079]$. No significant 246 differences for baseline characteristics were observed between patients with and without 247 echocardiographic data (data not shown).

248 To note, SLE patient did not have LS endocarditis at baseline and was lost to follow-up. 
251 During follow-up, 46 (75.4\%) patients underwent transthoracic echocardiography at least once

252 (14 lost to follow-up, one death). Median follow-up between the first and last transthoracic

253 echocardiography was 72 months (range 12-252). Among the 46 patients, LS endocarditis 254 developed in $8(17.4 \%)$ during follow-up, and $26(42.6 \%)$ had LS endocarditis at the last 255 echocardiography. After 5 years of follow-up, 3 (6\%) had a new LS and the median follow-up 256 between baseline and the occurrence of LS endocarditis was 8 years (range 1-16). In total, 13 257 (28.3\%) patients showed significant worsening of cardiac status after a median follow-up of 13 258 years (range 1-16); worsening of valvular lesions was most frequently observed. Three patients 259 needed surgery: two valvular replacements (mitral and aortic respectively) and one ascending 260 aortic aneurysm operation. None of these patients had LS endocarditis. Among 33 patients 261 without LS endocarditis at baseline, neurological, cardiovascular and radiological features did 262 not differ between those with and without LS endocarditis during follow-up (Table 5). Of note, 263 no patient showing LS endocarditis during follow-up had a modification of the antithrombotic 264 treatment because of LS endocarditis.

\section{Risk of neurological relapse by LS endocarditis status}

267 Risk of neurological relapse during follow-up was not associated with presence of LS 268 endocarditis at baseline (HR: 1.20 [95\% CI: 0.35 to 4.01] p=0.90) (Figure 2A). Moreover, 269 among patients without LS endocarditis at baseline, risk of neurological relapse was not 270 associated with incidence of LS endocarditis during follow-up (HR: 0.38 [95\% CI: 0.09 to 1.60], $271 p=0.19)$ (Figure 2B).

272 After adjusting for antithrombotic treatment regimen (low-dose aspirin versus other treatments), 273 similar results were observed (HR: 1.06 [95\% CI: 0.33 to 4.74$] \mathrm{p}=0.92$ ) for LS endocarditis at 274 baseline and (HR: 0.38 [95\% CI: 0.02 to 1.89 ], $\mathrm{p}=0.31$ ) for LS endocarditis occurring during 275 follow-up. 
276 Among the 18 patients with LS endocarditis at baseline, $3(17 \%)$ had neurological relapse compared with $11(26 \%)$ in patients without LS endocarditis at baseline (Odds ratio (OR): 0.62 [IC 95\% 0.15 to 2.58 ], $\mathrm{p}=0.50$ ). Moreover, among the 8 patients who developed LS endocarditis during follow-up $1(12.50 \%)$ had relapse versus $8(32 \%)$ in patients who did not develop LS endocarditis (OR: 0.30 [IC 95\% 0.03-2.90], $\mathrm{p}=0.25$ )

\section{Discussion}

In this study, we describe the echocardiographic features of cardiac involvement in $\mathrm{PPL}^{-} \mathrm{SS}$ patients, with a long-term follow-up up to 27 years. We found a high prevalence of cardiac involvement, including HVD, LV diastolic dysfunction, left atrium dilatation or increased systolic pulmonary arterial pressure. HVD was the most frequent cardiac involvement, with a 291 high frequency of valvular thickening and regurgitation: $32.8 \%$ and $40.9 \%$ for the aortic valve 292 and $36.0 \%$ and $73.8 \%$ for the mitral valve, respectively.

293 The most common non-valvular alterations were LV relaxation impairment and left atrium 294 dilatation, with a prevalence of $39.0 \%$ for both. Although other causes of LV relaxation 295 impairment cannot be excluded (such as endomyocardial fibrosis), this finding is consistent 296 with a study focusing on echocardiography assessment of LV diastolic function in primary 297 APS $^{29}$.

298 During follow-up, 13 (28.3\%) patients showed significant cardiac worsening other than LS 299 endocarditis, including 2 (4\%) who required cardiac surgery for valvular replacement, which is 300 notable. This result is equivalent to that reported in a meta-analysis $\left({ }^{29}\right)$, finding that $3 \%$ of APS 
301 patients underwent valve replacement. Importantly, valvular replacement by mechanical 302 prosthesis or bioprosthesis has been widely described APS with or without SLE $\left({ }^{30-35}\right)$ but never 303 in aPL- SS. One patient underwent ascending aortic aneurysm surgery, even if the association 304 between SS and aortic aneurysm occurrence is unclear. Moreover, patients presenting 305 significant cardiac complications in our cohort had longer follow-up, which suggests that 306 regular and long-term cardiac follow-up is needed to detect complications, especially since 307 valvular degeneration may have a long period of being silent $\left({ }^{36}\right)$.

308 We observed a high prevalence of LS endocarditis in $\mathrm{aPL}^{-} \mathrm{SS}$ patients. Indeed, we found LS 309 endocarditis in $18(29.5 \%)$ patients at baseline. These results suggest that the prevalence of LS 310 endocarditis in $\mathrm{aPL}^{-} \mathrm{SS}$ may be higher than that reported in $\mathrm{aPL}^{+} \mathrm{SS}$, ranging from 6 to $10 \%$ in 311 several cohort studies including APS and/or SLE patients $\left({ }^{12-14}\right)$, to $23 \%$ in a meta-analysis 312 including aPL+ SLE patients $\left({ }^{37}\right)$.

313 The occurrence of LS endocarditis during follow-up was not uncommon in our series $n=8$

314 (17.4\%). Neither the presence of LS endocarditis at baseline nor the development of new LS 315 during follow-up was associated with any clinical features or disease severity at baseline or 316 neurological relapse during follow-up. These results contrast with those observed in aPL $\mathrm{SS}^{+}$

317 Indeed, in a study assessing the association between ischemic cerebrovascular events and HVD 318 in patients presenting SLE, cerebrovascular events were associated with aPL positivity/APS, 319 and left-sided HVD $\left({ }^{38}\right)$. Consistent with these results, four other studies found a significant 320 association between valvular involvement including LS endocarditis and cerebrovascular 321 events in APS patients with or without SLE $\left({ }^{13,15,39,40}\right)$ with HR ranging from $3.88\left({ }^{13}\right)$ to 5.6 $322\left({ }^{15}\right)$. No study has assessed the risk of neurological relapse with LS development during follow323 up in APS patients. We did not observe any change in the neurological outcomes in patients 324 with the occurrence of LS endocarditis during follow-up suggesting that a new LS endocarditis 325 seemed not to increase the risk of neurological relapse in $\mathrm{aPL}^{-} \mathrm{SS}$ patients. This result is in 
accordance with recent pathological autopsy findings showing that strokes are caused by "insitu" vasculopathy of cerebral arteries rather than an embolic etiology associated with LS endocarditis $\left({ }^{11}\right)$.

However, the main limitation of this study is the relatively low number of included patients as well as the low number of neurological relapses. Therefore, the absence of difference observed may be related to the small sample size. Indeed, to detect as significant a HR of 4 (respectively 3 ), in line with estimated association in $\operatorname{APS}\left({ }^{13}, 15\right)$, with a risk alpha of $5 \%$ and a power of $80 \%$ would require 50 (respectively 67) aPL-SS patients including 13 (respectively 17) with new LS endocarditis. Interestingly, in this study, the risk of neurological relapse was lower in the population of patients with new $\operatorname{LS}(\mathrm{HR}=0.38)$, and the higher boundary of the HR confidence interval (1.89) was lower than all HR found between LS and cerebrovascular events in APS, which may be a signal that this association is different in aPL- SS disease. Moreover, aPL- SS is a rare disease and this is the first study assessing the relationship between occurrence of LS endocarditis and neurological relapses with a long-term follow-up. In order to improve knowledge on this potential association, individual data of our patients are provided in a supplemental file and may be used for individual meta-analysis. Moreover, the age of patients may have affected results, particularly for patients in whom LS endocarditis developed during follow-up. Indeed, after age 50 years, it may be difficult to differentiate degenerative abnormalities and calcifications from LS endocarditis. Indeed, in patients in whom LS endocarditis developed during follow-up, the median age was 53.9 (range 39-66.9) including 2 patients who were $>60$ years old. Therefore, the prevalence of LS may have been overestimated. However, we used the validated criteria from Roldan et al. $\left({ }^{16}\right)$ and doubtful cases were excluded. Finally, the shorter follow-up duration between LS+ compared with LSendocarditis at baseline (147.2 months [12.4-386.7] vs 55.5 [3.6-221.5], $\mathrm{p}=0.004)$ may have impacted our results. However, no specific reasons were identified to explain this difference. 
In particular, only one death occurred in the LS+ endocarditis group. Moreover, in the new LS+ group similar follow-up duration was noted compared with no new LS endocarditis (177.4 months [63.8-239.4] vs. 147.2 [12.4-386.7], $\mathrm{p}=0.9)$. A strength of this study is the stability of antithrombotic treatment, thus avoiding time-varying confounding effect. Indeed, the modification of antithrombotic treatment because of the occurrence of a new LS endocarditis would have been an important confounding factor. However, in our cohort, treatment was never modified by the occurrence of LS endocarditis during follow-up. In particular, low-dose aspirin was not changed to a vitamin-K antagonist in these patients. From the available data regarding $\mathrm{aPL}^{+} \mathrm{SS}$, a switch to a vitamin-K antagonist may have been discussed. Indeed, the preventive treatment of ischemic stroke or TIA in patients meeting the criteria for APS is based on longterm vitamin-K antagonist therapy $\left({ }^{40}\right)$. In addition, although no study has specifically assessed the risk of stroke in $\mathrm{aPL}^{+} \mathrm{SS}$ with LS occurring during follow-up, as discussed earlier, the risk of stroke seems increased in $\mathrm{aPL}^{+} \mathrm{SS}$ with $\mathrm{LS}$ endocarditis $\left({ }^{13,38,39,41}\right)$. There is no current recommendation for the treatment of $\mathrm{aPL}^{-} \mathrm{SS}$. In the study of Francès et al., the number of cerebrovascular events per year did not differ in $\mathrm{aPL}^{-} \mathrm{SS}$ patients with low-dose aspirin or vitamin-K antagonist treatment. Thus, although no conclusion can be drawn based on our limited sample size, our data raise the hypothesis that LS endocarditis occurrence during follow-up should not lead to antithrombotic treatment escalation.

\section{Conclusion}

Cardiac involvement is frequent in $\mathrm{aPL}^{-} \mathrm{SS}$. Long-term follow-up is needed to detect complications after several years. No change in neurological relapse was observed in patients presenting LS endocarditis occurrence during follow-up without any modification in antithrombotic treatment. Further research is necessary to assess the usefulness of treatment escalation in these patients. 
377 Acknowledgment: The authors thank Laura Smales (BioMed Editing) for English medical 378 editing of the manuscript

379

\section{Authors contributions}

- Research design: SA, CF, FC

- Data acquisition: FA, DZ, LB, CF, FC

383

- Data analysis/interpretation: FA, DZ, ST, AB, FC, DC

\section{References}

1. Sneddon, I. B. CEREBRO-VASCULAR LESIONS AND LIVEDO RETICULARIS. $B r . J$. Dermatol. 1965; 77: 180-185

2. Zelger, B. Sepp N, Stockhammer G, Dosch E, Hilty E, Ofner D, et al. Sneddon's syndrome. A long-term follow-up of 21 patients. Arch Dermatol 1993; 129: 437-447

3. Wu, S., Xu, Z. \& Liang, H. Sneddon's syndrome: a comprehensive review of the literature. Orphanet J Rare Dis 2014; 9: 215

4. Kalashnikova LA, Nasonov EL, Borisenko VV, Usman VB, Prudnikova LZ, Kovaljov VU, et al. Sneddon's syndrome: cardiac pathology and antiphospholipid antibodies. Clin. Exp. 
400 5. Levine, S. R., Langer, S. L., Albers, J. W. \& Welch, K. M. Sneddon's syndrome: an $401 \quad$ antiphospholipid antibody syndrome? Neurology $1988 ; \mathbf{3 8}: 798-800$

402 6. Asherson, R. A. \& Cervera, R. Unusual manifestations of the antiphospholipid syndrome. 403 Clin Rev Allergy Immunol 2003; 25: 61-78

404 7. Sanna, G., D’Cruz, D. \& Cuadrado, M. J. Cerebral manifestations in the antiphospholipid 405 (Hughes) syndrome. Rheum. Dis. Clin. North Am. 2006; 32: 465-490

406 8. Miyakis S, Lockshin MD, Atsumi T, Branch DW, Brey RL, Cervera R, et al. International 407 consensus statement on an update of the classification criteria for definite antiphospholipid syndrome (APS). J Thromb Haemost. 2006; 2: 295-306

9. Schellong, SM, Weissenborn K, Niedermeyer J, Wollenhaupt J, Sosada M, Ehrenheim C, Lubach D. Classification of Sneddon's syndrome. VASA 1997; 26: 215-221

10. Francès C, Papo T, Wechsler B, Laporte JL, Biousse V, Piette JC Sneddon syndrome with or without antiphospholipid antibodies. A comparative study in 46 patients. Medicine (Baltimore) 1999; 78: 209-219

414 11. Berciano J, Terán-Villagrá N. . J Neurol. sept 2018;265(9):2143-5.

12. Krause I, Lev S, Fraser A, Blank M, Lorber M, Stojanovich L, et al. Close association between valvar heart disease and central nervous system manifestations in the antiphospholipid syndrome. Ann. Rheum. Dis. 2005; 64: 1490-1493

13. Moyssakis I, Tektonidou MG, Vasilliou VA, Samarkos M, Votteas V, Moutsopoulos HM. Libman-Sacks endocarditis in systemic lupus erythematosus: prevalence, associations, and

422 14. Roldan, C. A., Shively, B. K. \& Crawford, M. H. An echocardiographic study of valvular 423 heart disease associated with systemic lupus erythematosus. N. Engl. J. Med. 1996; 335: $1424-1430$ 
15. Roldan CA, Sibbitt WL Jr, Qualls CR, Jung RE, Greene ER, Gasparovic CM, et al. LibmanSacks endocarditis and embolic cerebrovascular disease. JACC Cardiovasc Imaging 2013; 6: $973-983$

16. Roldan CA, Tolstrup K, Macias L, Qualls CR, Maynard D, Charlton G, et al. Libman-Sacks Endocarditis: Detection, Characterization, and Clinical Correlates by Three-Dimensional Transesophageal Echocardiography. J Am Soc Echocardiogr 2015; 28: 770-779

17. Bottin L., Francès C, de Zuttere D, Boëlle PY, Muresan IP, Alamowitch S., Strokes in Sneddon syndrome without antiphospholipid antibodies. Ann. Neurol. 2015; 77: 817-829

18. Petri M, Orbai A-M, Alarcón GS, Gordon C, Merrill JT, Fortin PR, et al. Derivation and validation of the Systemic Lupus International Collaborating Clinics classification criteria for systemic lupus erythematosus. Arthritis Rheum. août 2012;64(8):2677-86.

19. Sacco RL, Kasner SE, Broderick JP, Caplan LR, Connors JJ, Culebras A, et al. An updated definition of stroke for the 21 st century: a statement for healthcare professionals from the American Heart Association/American Stroke Association. Stroke 2013; 44: 2064-2089

20. Lang RM, Badano LP, Mor-Avi V, Afilalo J, Armstrong A, Ernande L, et al. Recommendations for cardiac chamber quantification by echocardiography in adults: an update from the American Society of Echocardiography and the European Association of Cardiovascular Imaging. J Am Soc Echocardiogr. janv 2015;28(1):1-39.e14.

21. Nagueh SF, Smiseth OA, Appleton CP, Byrd BF, Dokainish H, Edvardsen T, et al. Recommendations for the Evaluation of Left Ventricular Diastolic Function by Echocardiography: An Update from the American Society of Echocardiography and the European Association of Cardiovascular Imaging. Eur Heart J Cardiovasc Imaging. 2016;17(12):1321-60. 
22. Marwick TH, Leano RL, Brown J, Sun JP, Hoffmann R, Lysyansky P, Becker M et al. Myocardial strain measurement with 2-dimensional speckle-tracking echocardiography: definition of normal range. JACC Cardiovasc Imaging 2009; 2: 80-84

23. Yingchoncharoen, T., Agarwal, S., Popović, Z. B. \& Marwick, T. H. Normal ranges of left ventricular strain: a meta-analysis. $J$ Am Soc Echocardiogr 2013; 26: 185-191

24. Wang Y, Yang H, Huynh Q, Nolan M, Negishi K, Marwick TH. Diagnosis of Nonischemic Stage B Heart Failure in Type 2 Diabetes Mellitus: Optimal Parameters for Prediction of Heart Failure. JACC Cardiovasc Imaging 2018; 11: 1390-1400

25. Lancellotti P, Tribouilloy C, Hagendorff A, Moura L, Popescu BA, Agricola E, et al. European Association of Echocardiography recommendations for the assessment of valvular regurgitation. Part 1: aortic and pulmonary regurgitation (native valve disease). Eur J Echocardiogr 2010; 11: 223-244

26. Baumgartner H, Falk V, Bax JJ, De Bonis M, Hamm C, Holm PJ, Iung B et al. 2017 ESC/EACTS Guidelines for the Management of Valvular Heart Disease. Rev Esp Cardiol (Engl Ed) 2018; 71: 110

27. Baumgartner H, Hung J, Bermejo J, Chambers JB, Evangelista A, Griffin BP, Iung B et al. Echocardiographic assessment of valve stenosis: EAE/ASE recommendations for clinical practice. J Am Soc Echocardiogr 2009; 22: 1-23; quiz 101-102

28. Coudray N, de Zuttere D, Blétry O, Piette JC, Wechsler B, Godeau P, Pourny JC, et al. M mode and Doppler echocardiographic assessment of left ventricular diastolic function in primary antiphospholipid syndrome. Br Heart $J$ 1995; 74: 531-535

29. Nesher, G., Ilany, J., Rosenmann, D. \& Abraham, A. S. Valvular dysfunction in antiphospholipid syndrome: prevalence, clinical features, and treatment. Semin. Arthritis Rheum. 1997; 27: 27-35 
30. Bouma W, Klinkenberg TJ, van der Horst IC, Wijdh-den Hamer IJ, Erasmus ME, Bijl M, et al. Mitral valve surgery for mitral regurgitation caused by Libman-Sacks endocarditis: a report of four cases and a systematic review of the literature. J Cardiothorac Surg 2010; 5: 13

31. Bai, Z., Hou, J., Ren, W. \& Guo, Y. Diagnosis and surgical treatment for isolated tricuspid Libman-Sacks endocarditis: a rare case report and literatures review. J Cardiothorac Surg 2015; 10: 93

32. Hachiya K, Wakami K, Tani T, Yoshida A, Suzuki S, Suda H, Ohte N. Double-valve replacement for mitral and aortic regurgitation in a Patient with Libman-Sacks endocarditis. Intern. Med. 2014; 53: 1769-1773

33. Samejima Y, Kodaka M, Ichikawa J, Mori T, Ando K, Nishiyama K, Komori M. Management of a Patient With Antiphospholipid Syndrome Undergoing Aortic Valve Replacement Using the Hepcon Hemostasis Management System Plus and Rotational Thromboelastometry: A Case Report. A A Case Rep 2017; 8: 100-104

34. Keenan, J. B., Rajab, T. K., Janardhanan, R., Larsen, B. T. \& Khalpey, Z. Aortic valve replacement for Libman-Sacks endocarditis. BMJ Case Rep 2016, (2016).

35. Nakasu, A., Ishimine, T., Yasumoto, H., Tengan, T. \& Mototake, H. Mitral valve replacement for Libman-Sacks endocarditis in a patient with antiphospholipid syndrome secondary to systemic lupus erythematosus. J Surg Case Rep 2018; rjy069

36. Diosteanu R, Schuler G, Müller U. Cardiac valve degeneration in a patient with

Sneddon syndrome. Clin Res Cardiol. juin 2015;104(6):453-5.

37. Zuily S, Regnault V, Selton-Suty C, Eschwège V, Bruntz JF, Bode-Dotto E et al. Increased risk for heart valve disease associated with antiphospholipid antibodies in patients with systemic lupus erythematosus: meta-analysis of echocardiographic studies. Circulation 2011; 124: 215-224 (2011). 
38. Morelli S, Bernardo ML, Viganego F, Sgreccia A, De Marzio P, Conti F et al. Left-sided heart valve abnormalities and risk of ischemic cerebrovascular accidents in patients with systemic lupus erythematosus. Lupus 2003; 12: 805-812

39. Roldan, C. A., Gelgand, E. A., Qualls, C. R. \& Sibbitt, W. L. Valvular heart disease as a cause of cerebrovascular disease in patients with systemic lupus erythematosus. Am. J. Cardiol. 2005; 95: 1441-1447 (2005).

40. Sacco RL, Adams R, Albers G, Alberts MJ, Benavente O, Furie K et al. Guidelines for prevention of stroke in patients with ischemic stroke or transient ischemic attack: a statement for healthcare professionals from the American Heart Association/American Stroke Association Council on Stroke: co-sponsored by the Council on Cardiovascular Radiology and Intervention: the American Academy of Neurology affirms the value of this guideline. Stroke 2006; 37: 577-617

41. Djokovic A, Stojanovich L, Stanisavljevic N, Banicevic S, Smiljanic D, Milovanovic B et al. Relationship between cerebrovascular and valvular manifestations in a Serbian cohort of patients with antiphospholipid syndrome. Clin. Exp. Rheumatol. 2018; 36: 850-855 (2018). 
Table 1. Baseline characteristics of the aPL-SS included patients $(n=61)$

\begin{tabular}{|l|l|}
\hline Follow-up (months), median (range) & $119(3.63-386.7)$ \\
\hline Female, $\mathrm{n}(\%)$ & $52(85 \%)$ \\
\hline Age at diagnosis (years), median(range) & $45(24-60)$ \\
\hline Neurological manifestation, n(\%) & \\
- Cerebral infarct (CI) & $41(67.2 \%)$ \\
- Transient ischemic attack (TIA) & $8(13.1 \%)$ \\
- Silent infarct & $2(3.3 \%)$ \\
- Hemorrhagic stroke (HS) & $1(1.6 \%)$ \\
- TIA+CI & $8(13.1 \%)$ \\
- TIA+CI+HS & $1(1.6 \%)$ \\
\hline Initial clinical manifestation, n (\%) & \\
- TIA/CI & $48(78.7 \%)$ \\
- Epilepsy & $1(1.6 \%)$ \\
- HS & $2(3.3 \%)$ \\
- Livedo & $6(9.8 \%)$ \\
- Neuropsychiatric & $3(4.9 \%)$ \\
- Thrombosis & $1(1.6 \%)$ \\
\hline Other neurological symptoms/complications, n (\%) & \\
- Epilepsy & $13(21 \%)$ \\
- Migraine & $22(36 \%)$ \\
- Cognitive impairment & $23(44 \%)$ \\
\hline Cardiovascular risk factors, n (\%) & \\
- High blood pressure & $34(55.7 \%)$ \\
- BMI> 25 & $30(49 \%)$ \\
- Diabetes mellitus & $2(3.3 \%)$ \\
- Tobacco smoking (current or former) & $35(57.4 \%)$ \\
- Dyslipidemia & $23(37.7 \%)$ \\
\hline Positive antinuclear autoantibodies >1/80, n (\%) & $18(30 \%)$ \\
Positive anti-DNA autoantibodies, $(\%)$ & $1(2 \%)$ \\
\hline First-line treatment for Sneddon, (\%) & $44(72 \%)$ \\
- Low-dose aspirin & $9(15 \%)$ \\
- Antiplatelet clopidogrel & $4(6 \%)$ \\
- Vitamin K antagonist & $4(6 \%)$ \\
- No antithrombotic treatment & \\
\hline
\end{tabular}

BMI: body mass index; NA: non available data; MTHFR: Methylenetatrahydrofolate Reductase; 
Table 2. Baseline results of transthoracic echocardiography of the aPL-SS patients ( $n=61)$

\begin{tabular}{|c|c|}
\hline $\begin{array}{l}\text { Aortic valve } \\
\text {-Bicuspidia, } \mathrm{n}(\%) \\
\text {-Valvular thickening, } \mathrm{n}(\%) \\
\text {-Calcification, } \mathrm{n}(\%) \\
\text {-Aortic stenosis, } \mathrm{n}(\%) \\
\text {-Moderate to severe aortic stenosis, } \mathrm{n}(\%) \\
\text {-Aortic regurgitation, } \mathrm{n}(\%) \\
\text {-Moderate to severe aortic regurgitation, n (\%) } \\
\text {-LS, n (\%) } \\
\text {-LS thickness (mm), median (range) } \\
\text { Mitral valve } \\
\text {-Valvular thickening, n (\%) } \\
\text {-Prolapse, } \mathrm{n}(\%) \\
\text {-Mitral regurgitation, n (\%) } \\
\text {-Moderate to severe mitral regurgitation, n (\%) } \\
\text {-Mitral stenosis, } \mathrm{n}(\%) \\
\text {-Moderate to severe mitral stenosis, n (\%) } \\
\text {-LS, n (\%) } \\
\text {-LS thickness (mm), median (range) }\end{array}$ & $\begin{array}{l}5(14.7 \%) \\
20(32.8 \%) \\
4(6.6 \%) \\
9(14.7 \%) \\
2(3.3 \%) \\
25(40.9 \%) \\
4(6.6 \%) \\
9(14.75 \%) \\
4(3-5.3)\end{array}$ \\
\hline $\begin{array}{l}\text { Left Ventricular Parameters } \\
\text {-EF\%, median (range) } \\
\text {-LVDD (mm), median (range) } \\
\text {-Interventricular septal wall thickness (mm), median (range) } \\
\text {-Posterior wall thickness (mm), median (range) } \\
\text {-LV mass }(\mathrm{g} / \mathrm{m} 2) \text {, median (range) } \\
\text {-LV mass index, median (range) } \\
\text {-LV dysfunction*, n (\%) } \\
\text {-LV relaxation dysfunction } \\
\text {-LV dilatation**, }(\%) \\
\text {-LV hypertrophy***, }(\%) \\
\text {-Peak longitudinal strain, median (range) } \\
\text { - SBHF criteria **** } \\
\text { at least one criteria, } \mathrm{n}(\%) \\
\text { all four criteria, } \mathrm{n}(\%)\end{array}$ & $\begin{array}{l}69(52-86) \\
48.7(38.4-59) \\
10.4(7.1-19.8) \\
9(6.7-15.4) \\
96.5(63-189) \\
0.37(0.27-0.57) \\
1(1.6 \%) \\
24(39 \%) \\
7(11 \%) \\
26(42 \%) \\
-20.95(-26.2 /-14.2) \\
47(80 \%) \\
0(0 \%)\end{array}$ \\
\hline $\begin{array}{l}\text { Left atrium dilatation } * * * * *, \mathrm{n}(\%) \\
\text { Left atrium volume }(\mathrm{mm}), \text { median (range) }\end{array}$ & $\begin{array}{l}16(39 \%) \\
33.5(25-56)\end{array}$ \\
\hline Systolic pulmonary arterial pressure $(\mathrm{mmHg})$, median (range) & $26.5(18-42)$ \\
\hline $\begin{array}{l}\text { Overall LS, } \mathrm{n}(\%) * * * * * * \\
\text { Age at LS diagnosis (years), median (range) }\end{array}$ & $\begin{array}{l}18(29.5 \%) \\
46.9(28-64)\end{array}$ \\
\hline Patients with at least one follow-up echocardiography, $\mathrm{n}(\%)$ & $46(75.4 \%)$ \\
\hline
\end{tabular}

$\mathrm{EF} \%$ : left ventricular ejection fraction, LVDD: left ventricular end diastolic diameter; *LV dysfunction defined by FE $\%<55 \%$; LS: Libman-Sacks endocarditis; ** Left ventricular enlargement: end-diastolic diameter $>56 \mathrm{~mm}$; *** Left ventricular hypertrophy: LVMi/BSA $>115 \mathrm{~g} / \mathrm{m}^{2}$ for men and $>95 \mathrm{~g} / \mathrm{m}^{2}$ for women; **** Stage B heart

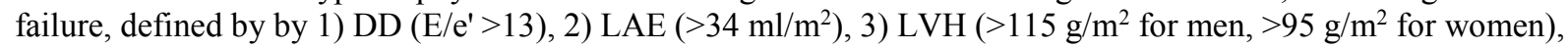


and 4) impaired GLS (cutoff $-16 \%$ ) $* * * * *$ Left atrial dilatation: left atrial index $>34 \mathrm{ml} / \mathrm{m}^{2} ; * * * * * *$ two patients had both aortic and mitral LS 
Table 3. Univariate analysis between patients with or without Libman-Sacks endocarditis at Baseline (n=61)

\begin{tabular}{|c|c|c|c|}
\hline Features & $\begin{array}{c}\text { Baseline LS+ } \\
\quad(n=18)\end{array}$ & $\begin{array}{c}\text { Baseline LS- } \\
\quad(n=43)\end{array}$ & p-value \\
\hline $\begin{array}{l}\text { Socio-demographic features } \\
\text {-Female sex, } \mathrm{n}(\%) \\
\text {-Age at diagnosis, median (range) } \\
\text {-Age at livedo development, median } \\
\text { (range) } \\
\text {-Age at first stroke, median (range) }\end{array}$ & $\begin{array}{l}17(94 \%) \\
41.5(28-56) \\
29(10-48) \\
40(23-56)\end{array}$ & $\begin{array}{l}35(81 \%) \\
46(24-60) \\
34(10-57) \\
55(24-58) \\
\end{array}$ & $\begin{array}{l}0.26 \\
0.10 \\
0.13 \\
0.23 \\
\end{array}$ \\
\hline $\begin{array}{l}\text { Cardiovascular risk factors } \\
\text {-BMI > 25, n (\%) } \\
\text {-HBP, n (\%) } \\
\text {-Dyslipidemia, (\%) } \\
\text {-Diabetes mellitus, n(\%) } \\
\text {-Smokers (current or former), n (\%) }\end{array}$ & $\begin{array}{l}6(33 \%) \\
10(55 \%) \\
5(28 \%) \\
0(0 \%) \\
10(56 \%) \\
\end{array}$ & $\begin{array}{l}24(56 \%) \\
24(56 \%) \\
18(42 \%) \\
2(5 \%) \\
25(58 \%) \\
\end{array}$ & $\begin{array}{l}0.11 \\
0.99 \\
0.30 \\
1 \\
0.85 \\
\end{array}$ \\
\hline $\begin{array}{l}\text { Neurological features } \\
\text { - Number of CI, median (range) } \\
\text { - Number of TIA, median (range) } \\
\text { - Epilepsy, n (\%) } \\
\text { - Migraine, n (\%) } \\
\text { - Cognitive impairment, n (\%) }\end{array}$ & $\begin{array}{l}1(1-2) \\
2(1-6) \\
3(16.7 \%) \\
8(44.4 \%) \\
7(43.7 \%) \\
\end{array}$ & $\begin{array}{l}1(1-4) \\
1(1-2) \\
10(23.3 \%) \\
14(32.6 \%) \\
16(44.4 \%) \\
\end{array}$ & $\begin{array}{l}0.11 \\
0.06 \\
0.73 \\
0.38 \\
0.96 \\
\end{array}$ \\
\hline $\begin{array}{l}\text { Cardiovascular features } \\
\text { - Coronary heart disease, } \mathrm{n}(\%) \\
\text { - Atrial fibrillation, } \mathrm{n}(\%) \\
\text { - Deep venous thrombosis/pulmonary } \\
\text { embolism, } \mathrm{n}(\%)\end{array}$ & $\begin{array}{l}0(0 \%) \\
0(0 \%) \\
2(11.8 \%)\end{array}$ & $\begin{array}{l}5(11.6 \%) \\
3(7.0 \%) \\
4(9.3 \%)\end{array}$ & $\begin{array}{l}0.31 \\
0.55 \\
1.00\end{array}$ \\
\hline Kidney dysfunction, n (\%) & $2(11.8 \%)$ & $7(16.3 \%)$ & 1.00 \\
\hline $\begin{array}{l}\text { Radiological features } \\
\text { - Number of radiological CI, median } \\
\text { (range) } \\
\text { - Number of radiological lacunar } \\
\text { stroke, median (range) } \\
\text { - White matter changes*, median } \\
\text { (range) }\end{array}$ & $\begin{array}{l}2(1-4) \\
2(1-14) \\
9(4-18)\end{array}$ & $\begin{array}{l}2(1-6) \\
1(1-3) \\
8(0-23)\end{array}$ & $\begin{array}{l}0.54 \\
0.19 \\
0.70\end{array}$ \\
\hline Raynaud phenomenon, n (\%) & $13(72 \%)$ & $16(37 \%)$ & $0.0125 * *$ \\
\hline ANA $\geq 1 / 160, \mathrm{n}(\%)$ & $8(46 \%)$ & $10(24 \%)$ & 0.079 \\
\hline Complement deficiency, n (\%) & $4(24 \%)$ & $3(7 \%)$ & 0.18 \\
\hline $\begin{array}{l}\text { First received treatment } \\
\text {-LDA, n (\%) } \\
\text {-Antiplatelet clopidogrel, n (\%) } \\
\text {-Vitamin K antagonist, n (\%) }\end{array}$ & $\begin{array}{l}14(78 \%) \\
2(12 \%) \\
2(12 \%) \\
\end{array}$ & $\begin{array}{l}30(70 \%) \\
7(16 \%) \\
4(9 \%)\end{array}$ & $\begin{array}{l}0.76 \\
1 \\
1 \\
\end{array}$ \\
\hline Follow-up months, median (range) & $55.5(3.6-221.5)$ & $147.2(12.4-386.7)$ & $0.004 * *$ \\
\hline
\end{tabular}

LS: Libman-Sacks endocarditis; BMI: body mass index; HBP: high blood pressure; ANA: antinuclear autoantibodies; LDA: low dose aspirin; CI: cerebral infarct; TIA: transient ischemic attack; * White matter changes assessed by Scheltens score; $* *$ Statistically significant in exploratory analysis but not after Bonferroni correction 
Table 4. Characteristics of the aPL-SS patients with at least one transthoracic echography during follow-up $(n=46)$

\begin{tabular}{|c|c|c|c|}
\hline \multicolumn{2}{|l|}{ Features } & \multicolumn{2}{|l|}{$\mathbf{N}(\%)$} \\
\hline \multicolumn{2}{|c|}{$\begin{array}{l}\text { Time between first and last transthoracic echocardiography (months), } \\
\text { median (range) }\end{array}$} & \multicolumn{2}{|l|}{$72(12-252)$} \\
\hline \multicolumn{2}{|l|}{ New LS development, $\mathrm{n}(\%)$} & \multicolumn{2}{|l|}{$8(17.4 \%)$} \\
\hline \multicolumn{2}{|c|}{$\begin{array}{l}\text { LS on last transthoracic echocardiography, } \mathrm{n}(\%) \\
\text { Age at new LS development (years), median (range) }\end{array}$} & \multicolumn{2}{|l|}{$\begin{array}{l}26(42.6 \%) \\
53.8(39-66.9)\end{array}$} \\
\hline $\begin{array}{l}\text { Significant worsening (other than L } \\
\text { New mitral regurgitation } \\
\text { Mitral regurgitation worsening } \\
\text { New aortic regurgitation } \\
\text { Aortic stenosis worsening } \\
\text { Ascending aortic aneurysm } \\
\text { New LV dysfunction } \\
\text { LV hypertrophy worsening } \\
\text { LV relaxation dysfunction worsenin }\end{array}$ & patients $(\%)$ & $\begin{array}{l}13(28.3 \%) * \\
2(4 \%) \\
2(4 \%) \\
3(6 \%) \\
2(4 \%) \\
2 * *(4 \%) \\
1(2 \%) \\
2(4 \%) \\
2(4 \%)\end{array}$ & \\
\hline \multicolumn{2}{|l|}{$\begin{array}{l}\text { Cardiac surgery, } \mathrm{n}(\%) \\
\text { - Valvular replacement } \\
\text { - Ascending aortic aneurysm }\end{array}$} & \multicolumn{2}{|l|}{$\begin{array}{l}3(6.5 \%) \\
2(4 \%) \\
1(2 \%)\end{array}$} \\
\hline Features & Significant worsening & No significant worsening & p-value \\
\hline Follow-up, months median (range) & $156(21-252)$ & $60(21-252)$ & 0.03 \\
\hline Features & LS occurence & No LS occurence & p-value \\
\hline Follow-up, months median (range) & $177.4(63.8-239.4)$ & $147.2(12.4-386.7)$ & 0.9 \\
\hline
\end{tabular}

* Some patients had more than one significant worsening, ** one patient needed surgery 
Table 5. Univariate analysis between patients with or without occurence of Libman-Sacks endocarditis during follow-up among patients without LS at baseline and available follow-up data $(n=33)$

\begin{tabular}{|l|l|l|l|}
\hline Features & New LS + & No New LS & p-value \\
\hline Neurological features & & & \\
- Number of CI, median (range) & $1(1-2)$ & $1(1-4)$ & 0.21 \\
- Number of TIA, median (range) & $1(1-1)$ & $1(0-2)$ & 1.00 \\
- Epilepsy, n (\%) & $3(37.5 \%)$ & $5(20 \%)$ & 0.37 \\
- Migraine, n (\%) & $4(50 \%)$ & $8(32 \%)$ & 0.42 \\
- Cognitive impairment, n (\%) & $2(28.6 \%)$ & $10(47.6 \%)$ & 0.66 \\
\hline Cardiovascular features & & & \\
- Coronary heart disease n (\%) & $0(0 \%)$ & $4(16 \%)$ & 0.55 \\
- Atrial fibrillation, n (\%) & $0(0 \%)$ & $2(8 \%)$ & 1.00 \\
- Deep venous thrombosis/pulmonary embolism, n & $2(25 \%)$ & $2(8 \%)$ & 0.24 \\
(\%) & & & \\
\hline Kidney dysfunction, n (\%) & $1(12.5 \%)$ & $4(16 \%)$ & 1.00 \\
\hline $\begin{array}{l}\text { Radiological features } \\
\text { - Number of radiological CI, median (range) }\end{array}$ & $3.5(1-6)$ & $2.5(1-5)$ & 0.43 \\
- Number of radiological lacunar stroke, median & $1.5(1-2)$ & $1(1-10.5)$ & 0.82 \\
(range) & & & \\
- White matter changes*, median (range) & $12(1-21)$ & $7(0-18.8)$ & 0.39 \\
- Significant worsening, n (\%) & $1(12.5 \%)$ & $10(40 \%)$ & 0.22 \\
\hline
\end{tabular}

LS: Libman-Sacks endocarditis; CI: cerebral infarct; TIA: transient ischemic attack * White matter changes assessed by Scheltens score 


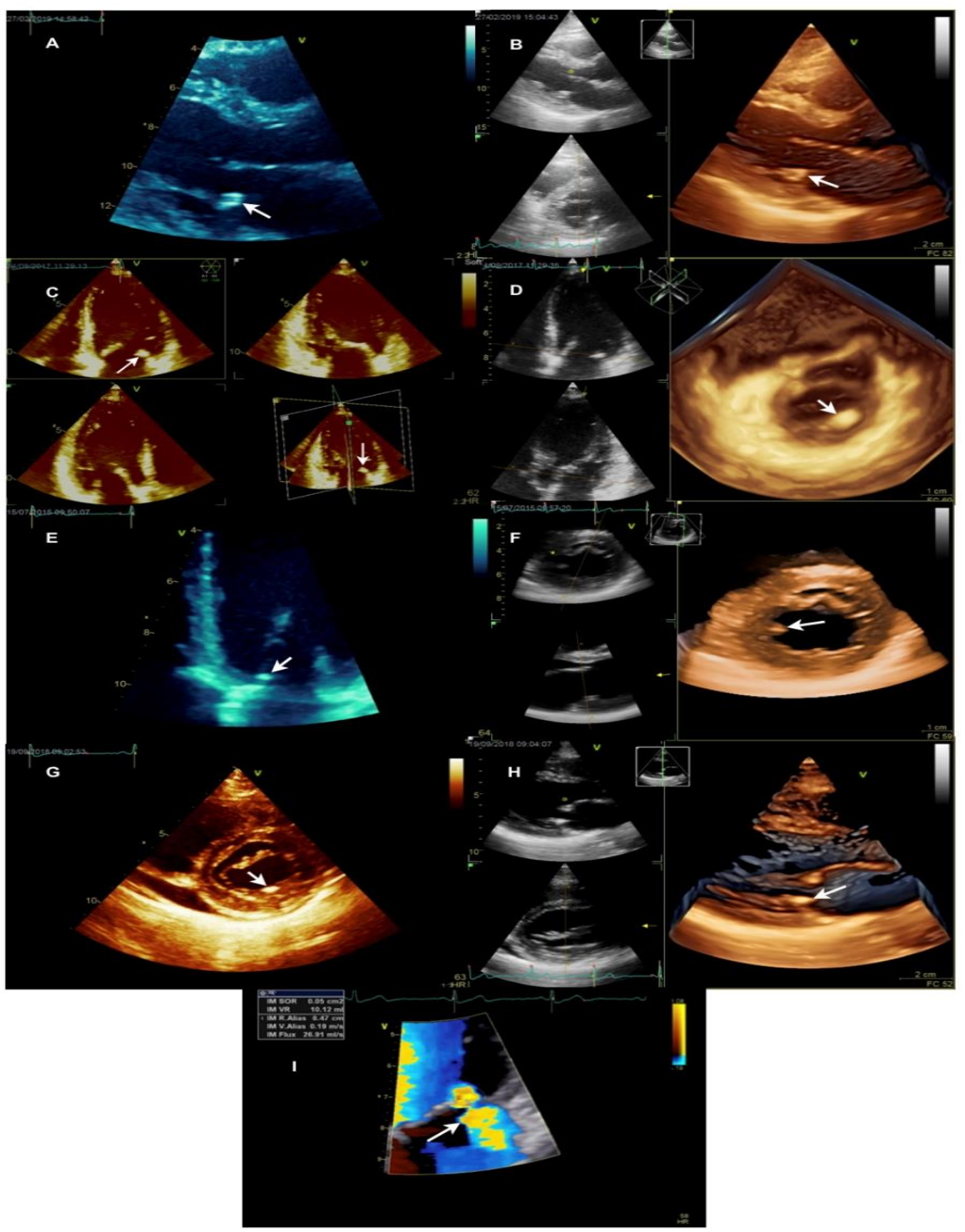

Figure 1 - Typical mitral abnormalities in Sneddon syndrome without antiphospholipid antibodies

$\mathrm{A}$ and B: patient PC, female, 53 years; (A) two-dimensional transthoracic echocardiography (2DTTE), parasternal long-axis view, zoomed image of the mitral valve with a Libman-Sacks vegetation (LSV) at the root, atrial side, of the posterior leaflet (arrow); (B) the same vegetative lesion (arrow) displayed with real-time three-dimensional transthoracic echocardiography (3DTTE).

$\mathrm{C}$ and D: patient AB, female, 31 years; (C) triplane (real-time 3DTTE-derived) two-dimensional apical views (4chamber, 2-chamber and 2-chamber with aorta), mitral valve with a LSV (arrow) at the root, atrial side, of the posterior leaflet; (D) the same vegetative lesion (arrow) displayed with 3DTTE, parasternal short-axis view (arrow). E and F: patient CC, female, 43 years; (E) 2DTTE, apical 4-chamber view, zoomed image of the mitral valve with a LSV attached to the posterior commissure (arrow); (F) the same vegetative lesion (arrow) displayed with real-time 3DTTE, parasternal short-axis view (arrow).

G to I: patient MG, male 54 years; (G) 2DTTE, parasternal short-axis view, showing a LSV (arrow) attached to the root, left atrial side, of the mitral valve posterior leaflet; $(\mathrm{H})$ real-time 3DTTE, parasternal long-axis view showing a LSV attached to the root, atrial side, of the mitral valve posterior leaflet; (I) transthoracic two-dimensional color Doppler flow recording of a small volume mitral regurgitation (arrow); radius of the proximal isovelocity convergence region $=4.7 \mathrm{~mm}$. 
Figure 2

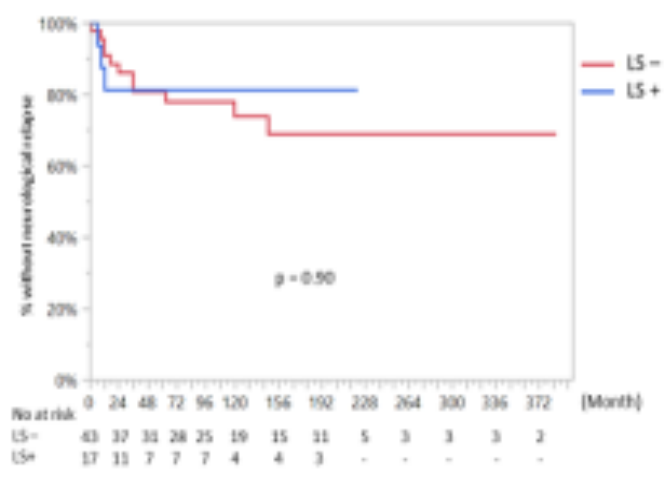

Figure 2A

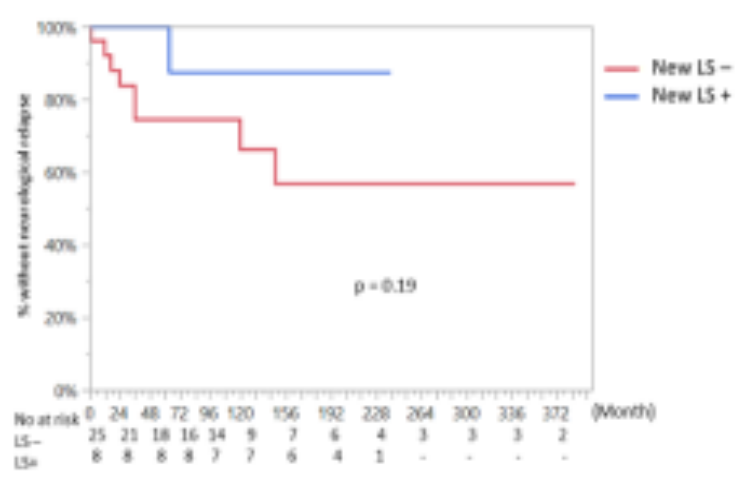

Figure 2B

Figure 2 legends:

Figure 2. 2.A: Kaplan-Meier curves for probability of neurological relapse over time stratified by presence or absence of LS at baseline. 2.B: Kaplan-Meier curves for probability of neurological relapse over time stratified by the occurrence or not of a new LS during follow-up 